\title{
Proceeding
}

Supplementary Issue: Spring Conferences of Sports Science. Costa Blanca Sports Science Events, 19-20 June 2020. Alicante, Spain.

\section{Effect of training on street simulators with variable load on the strength women and men in powerlifting}

\author{
ROMAN SERGEEVICH NAGOVITSYN ${ }^{1}$, ALEKSANDER YURIEVICH OSIPOV ${ }^{2}$, MIKHAIL DMITRIEVICH \\ KUDRYAVTSEV ${ }^{3}$, LARISA VYACHESLAVOVNA ZAKHAROVA ${ }^{4}$, NATAL'YA VLADIMIROVNA LYULINA ${ }^{4}$ \\ ${ }^{1}$ Glazov State Pedagogical University, Glazov, Russian Federation \\ ${ }^{2}$ Department of Physical Culture, Siberian Federal University, Krasnoyarsk State Medical University named after \\ professor V.F. Voyno-Yasenetsky, Siberian Law Institute of the Ministry of Internal Affair of Russia, Russian Federation \\ ${ }^{3}$ Department of Physical Culture, Siberian Federal University, Reshetnev Siberian State University of Science and \\ Technology, Siberian Law Institute of the Ministry of Internal Affair of Russia, Russian Federation \\ ${ }^{4}$ Department of Physical Culture, Siberian Federal University, Russian Federation
}

\begin{abstract}
Background: The training process to develop the strength of athletes on street exercise simulators with a variable load for powerlifting is not a systematically studied problem. The aim of the study was to analyse the impact of systematic training on street simulators with a variable load on the strength indicators of women and men in powerlifting. Study participants: athletes from 20 to 35 years old $(n=48)$, engaged in powerlifting at least four times a week, divided into groups: women $(n=24)$ and men $(n=24)$. Interventions: Implementation of systematic exercises for women and men in powerlifting on street exercise simulators with variable load for five months. For the performance diagnosis, the powerlifter coefficient (PI) was applied: (bench press + sed + deadlift) / athlete's mass in kilograms. Main outcome measures: the experiment revealed a positive result in increasing the strength of men $(p<.05)$ and did not reveal a reliable result $(p>.05)$ in increasing the strength in women between the control and experimental groups. Based on an individual comparison of each participant in the experimental group, it was revealed that the implementation of the street training process is significantly $(p<.01)$ more effective in increasing strength in men with a Pl coefficient below the average $(<3.53)$. Findings. The data obtained are especially valuable in the condition of the activation of street fitness among women and men in the conditions of the closure of gyms caused by the regime of self-isolation during the spread of COVID-19.

Keywords: Street fitness equipment; Powerlifting; Strength; Coefficient.

Cite this article as:

Nagovitsyn, R.S., Osipov, A.Y., Kudryavtsev, M.D., Zakharova, L.V. \& Lyulina, N.V. (2020). Effect of training on street simulators with variable load on the strength women and men in powerlifting. Journal of Human Sport and Exercise, 15(3proc), S471-S480. doi:https://doi.org/10.14198/jhse.2020.15.Proc3.01

Corresponding author. Glazov State Pedagogical University, Glazov, Russian Federation. http://orcid.org/0000-0003-4471$\underline{0875}$

E-mail: gto18@mail.ru

Supplementary Issue: Spring Conferences of Sports Science. Costa Blanca Sports Science Events, 19-20 June 2020. Alicante, Spain.

JOURNAL OF HUMAN SPORT \& EXERCISE ISSN 1988-5202

(c) Faculty of Education. University of Alicante

doi:10.14198/jhse.2020.15.Proc3.01
\end{abstract}




\section{INTRODUCTION}

Today, in various studies, the problem of reducing the level of physical development of student and working youth is actively popularized (Osipov et al., 2018). In connection with a decrease in the physical activity of the population, scientific and theoretical and methodological work on the search for effective technologies to increase the motivation of young people for an active lifestyle is being activated (Chow et al., 2017; Kudryavtsev et al., 2016). Public activities to increase the number of people actively involved in physical education and sports are increasing and becoming more relevant (Copeland et al., 2017; Nagovitsyn et al., 2019) through the systematization of information work and the availability of physical activities anytime, anywhere (Bedimo-Rung et al ., 2005; Calogiuri \& Elliott, 2017). In this direction, the use of a street space equipped with special street training devices can help to solve the presented problem (Babey et al., 2008; Copeland et al., 2017).

Systematic physical activity on street exercise machines can not only enhance the physical qualities and abilities of a person, but also increase the level of athletic performance (Lacharite-Lemieux \& Dionne, 2016; Kharisov et al., 2017). The training process on special street simulators can replace strength training in a special gym in some sports (Taipe-Nasimba et al., 2019; Thompson et al., 2011). In this aspect, one of the mass and affordable power sports is powerlifting (Lesuer et al., 1997). Powerlifting or powerlifting is based on overcoming the maximum weight resistance for an athlete (Coker et al., 2018). As competitive disciplines, it includes three exercises (Ogulchansky \& Sedyh, 2017). Which in total determine the athlete's qualifications: squats with a barbell on the back (on the upper part of the shoulder blades), a bench press lying on a horizontal bench and a deadlift barbell (Radenkovic \& Nesic, 2018). These types of exercises are called "basic" for the development of strength, since when they are executed, several joints and almost all muscles are included in the work (Yarmak et al., 2018; Yakubenko, 2016). They are recommended for beginner athletes to gain overall muscle mass and develop strength (Galan et al., 2017; Osipov et al., 2017).

An analysis of special theoretical and methodological literature (Aspinall et al., 2015; Nagovitsyn et al., 2017) reveals a contradiction between insufficient conditions for mass lifting power lifting on the one hand (Church et al., 2016; Ogulchansky \& Sedyh, 2017). And significant opportunities for practicing power sports on street simulators in parks and in the community using special outdoor equipment on the other hand (SanchezMartinez et al., 2017; Kharisov et al., 2017). Every year, the increasing number of outdoor exercise machines located in urban environments and in parks in many countries aims to stimulate physical activity among the population (Babey et al., 2008; Sibson et al., 2018). However, little studied aspects are the sports experience of youth who are actively involved in sports regarding the use of these funds (Hug et al., 2009). Many researchers (Cranney et al., 2016; Ries et al., 2009) substantiate the positive relationship between the accessibility of a recreational facility in a city park and the physical activity of youth in a strong direction (Babey et al., 2008). The studies (Allen-Collinson \& Leledaki, 2015; Chow \& Wu, 2019) offer various systems of free street power fitness, built on the basis of self-employment using virtual mentors and various mobile content (Nagovitsyn et al., 2018). Nevertheless, a number of researchers (Manferdelli et al., 2019; Şar et al., 2018) prove that the main reason for the low attendance of park areas with fitness simulators by the population is the insufficient attention of municipal departments of physical education and sports and sports federations to this issue (Nagovitsyn et al., 2019).

Thus, the scientific community is actively raising the issue of systematizing the street training process (Calogiuri \& Elliott, 2017; Thomson et al., 2011) and increasing the mass of the process of physical exercises on street exercise machines in the fresh air (Garipova et al., 2017; Sibson et al., 2018). However, the implementation of the training process in powerlifting on special street simulators with a variable load at the 
place of residence remains without attention of researchers. In this regard, the aim of the study is to analyse the impact of systematic training on street simulators with a variable load on the strength indicators of women and men in powerlifting.

\section{MATERIAL AND METHODS}

\section{Participants}

The study participants were athletes from 20 to 35 years old $(n=48)$, engaged in powerlifting at least four times a week. All study participants have no contraindications to the maximum physical activity of the force direction. Each study participant had a basic level of technical and tactical training in performing physical exercises in powerlifting. Athletes were divided by gender: women $(n=24)$ and men $(n=24)$. In turn, each group based on a random sample was divided into two equal groups: the experimental group (EG) and the control group (CG).

The solution of research problems was provided by a set of complementary theoretical methods for the analysis of Russian and foreign pedagogical theory, practice and experience in the field of physical culture and sports activities on street exercise machines. For the study, classification, modelling, comparison, comparison and generalization, observation using diagnostic tools and video fixation were used.

Based on the study of special literature on diagnostics in powerlifting (Ball \& Weidman, 2018; Cleather, 2006; Coker et al., 2018; Lesuer et al., 1997), a simple powerlifter coefficient (PI) for calculation and daily selfmonitoring was applied: (bench press + sed + deadlift) / athlete mass in kilograms.

\section{Statistical analysis}

Processing the results of the study was carried out using the statistical program SPSS20. The significance of differences in the results was determined using Student's T-test at $p<.01$ and $p<.05$. Mathematical and statistical data processing was carried out between the obtained indicators of the control and experimental groups before and after the experiment and for each group of girls and boys.

\section{RESULTS}

The experiment was implemented on the basis of the Progress Municipal Sports Institution in Glazov, the Udmurt Republic, Russia. All study participants implemented the same powerlifting training process for five months (May 2019 - September 2019) for weekly and monthly cycles. The experimental group implemented the training process on street simulators under the guidance of a coach or mentor. In the preparatory and final part of the powerlifting classes, simulators were used without changing the weight load and workouts. In the main part of the physical exercise, exercise machines with variable load for powerlifting and for various muscle groups were used. The control group carried out the training process in a specialized gym in a standard annual mode under the guidance of the on-duty trainer in the gym or on their own.

Power Trainers for Powerlifting are shown in Figure 1: 


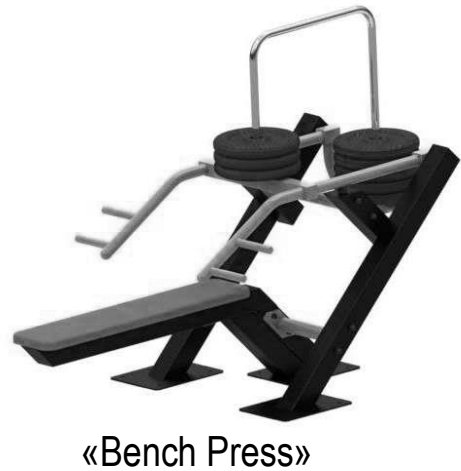

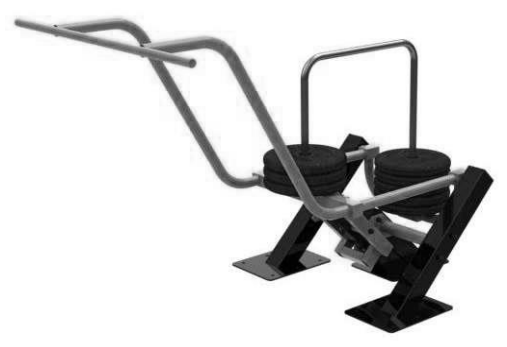

«Sed»

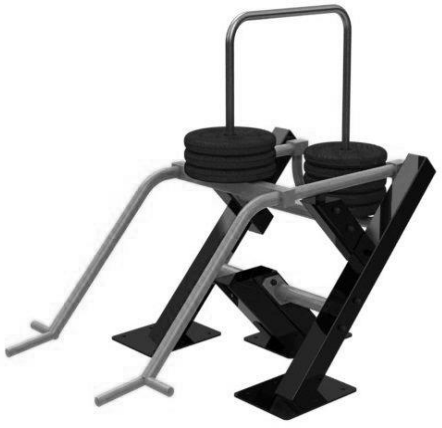

«Deadlift»

Figure 1. Street exercise simulators with a variable load for powerlifting.

Before the start of the experiment (May 2019) and after the implementation of the study (September 2019), power diagnostics for sports types of powerlifting was implemented. All participants in the study took part in the monitoring. Athletes performed three exercises without equipment: squatting with a barbell on the back (on the upper part of the shoulder blades), a bench press lying on a horizontal bench and a barbell pull. The results in total determined the sportsman's athletic level. To summarize, the average powerlifter coefficient (PI) was applied in each study group of athletes. Prior to the implementation of the study (May 2019), a statistical analysis of the data revealed an unreliability $(p>.05)$ of the difference between the EG and the CG for both the group of women and the group of men. The results of the experiment are presented in Table 1 for women and in Table. 2 for men.

Table 1. The results of the average coefficient of powerlifters (PI) in women of the EG and CG.

\begin{tabular}{lcccc}
\hline Group & May 2019 & September 2019 & temp & $p$ \\
\hline EG & $2.71 \pm 0.69$ & $3.17 \pm 0.81$ & 2.14 & $<.05$ \\
CG & $2.81 \pm 0.78$ & $3.37 \pm 1.09$ & 2.12 & $<.05$ \\
temp & 0.57 & 0.76 & & \\
$p$ & $>.05$ & $>.05$ & & \\
\hline
\end{tabular}

Table 2. The results of the average coefficient of powerlifters $(\mathrm{PI})$ in men EG and CG.

\begin{tabular}{lcccc}
\hline Group & May 2019 & September 2019 & temp & $p$ \\
\hline EG & $3.53 \pm 0.59$ & $4.36 \pm 0.79$ & 4.61 & $<.01$ \\
CG & $3.46 \pm 0.63$ & $3.87 \pm 0.88$ & 1.91 & $>.05$ \\
temp & 0.43 & 2.18 & & \\
p & $>.05$ & $<.05$ & & \\
\hline
\end{tabular}

Based on the results of the average powerlifters $(\mathrm{PI})$ coefficient for women groups, a significant positive effect was found from the implementation of the training process with a significance of $p<.05$ in both groups: experimental and control (Table 1). During the study period, women engaged in street fitness equipment and in a special gym statistically increased the results of their strength indicators. Statistical analysis substantiated the effectiveness of powerlifting exercises on street exercise machines with a variable load on the strength indicators in women. Nevertheless, the received not reliable result in September 2019 with a significance level of $p>.05$, shows a comparative between the EG and the CG is not the effectiveness of the study for a group of women. This result can be explained by the fact that the street space for physical exercises does not have a sufficient stimulating effect on the power activity of women. 
Analysis of the strength indicators of men based on the results of the average powerlifters (PI) coefficient for groups revealed a positive effect from the implementation of the training process in increasing the strength of men in both groups: experimental and control (Table 2). However, the statistical analysis determined the reliability of comparing the values $(p<.01)$ before the experiment (May 2019) and after (September 2019) only in the experimental group. In turn, in the control group, a comparative study of the values before and after the study period showed no significant difference at $p>.05$. A statistical comparative analysis of the EG and CG in September 2019 reliably ( $p>$.05) substantiated the effectiveness of powerlifting exercises on street simulators with a variable load on strength indicators in men. This result can be explained by the fact that the street space for physical exercises has a motivating effect on the motor activity of men in the power direction. As the experiment showed, fresh air and female spectators, systematically observing the training process, became positive conditions for the effectiveness of the experiment.

For a more detailed analysis of the impact of powerlifting on street simulators with a variable load on the strength indicators in women and men, the individual indicators of each athlete of the experimental group were studied. Based on a preliminary identification (May 2019) of the average values of the PI coefficient for women (2.71) and for men (3.53), the EG was divided in equal numbers into four groups: women with $\mathrm{PI}<$ 2.71; women - $\mathrm{PI}>2.71$; men $-\mathrm{PI}<3.53$; men $-\mathrm{PI}>3.53$. The individual results of each athlete in focus groups $(n=4)$ before the experiment (May 2019) and after it (September 2019) are presented in Table 3:

Table 3. The results of the individual coefficient of powerlifters (PI) in women and men EG.

\begin{tabular}{|c|c|c|c|c|c|c|c|c|}
\hline Participants & 1 & 2 & 3 & 4 & 5 & 6 & temp & $p$ \\
\hline \multicolumn{9}{|c|}{ Women EG $\left(\mathrm{PI}^{*}<2.71\right)$} \\
\hline May 2019 & 2.02 & 2.12 & 2.15 & 2.41 & 2.51 & 2.65 & \multirow{2}{*}{2.82} & \multirow[t]{2}{*}{$<.05$} \\
\hline September 2019 & 2.51 & 2.41 & 3.44 & 2.57 & 3.17 & 3.88 & & \\
\hline \multicolumn{9}{|c|}{ Women EG $\left(\mathrm{PI}^{*}>2.71\right)$} \\
\hline May 2019 & 2.72 & 3.03 & 3.09 & 3.22 & 3.25 & 3.4 & 0.94 & $>.05$ \\
\hline September 2019 & 2.36 & 3.51 & 2.79 & 3.81 & 3.63 & 3.98 & & \\
\hline \multicolumn{9}{|c|}{ Men EG $\left(\mathrm{PI}^{*}<3.53\right)$} \\
\hline May 2019 & 2.94 & 2.99 & 3.01 & 3.13 & 3.42 & 3.44 & 4.82 & $<.01$ \\
\hline September 2019 & 3.76 & 3.57 & 4.71 & 4.39 & 5.01 & 4.48 & & \\
\hline \multicolumn{9}{|c|}{ Men EG $\left(\left.P\right|^{*}>3.53\right)$} \\
\hline May 2019 & 3.67 & 3.71 & 3.79 & 4.01 & 4.07 & 4.12 & 2.74 & $<.05$ \\
\hline September 2019 & 3.99 & 4.25 & 4.32 & 4.19 & 4.46 & 5.15 & & \\
\hline
\end{tabular}

An analysis of the data revealed significant differences between the increase in strength indicators in athletes who have different power levels in powerlifting before the experiment. The implementation of the street training process is effective in increasing strength in women with a PI coefficient below average $(<2.71)$, compared with women with a PI coefficient above average $(>2.71)$ in significance $(p<.05)$. In turn, when men practiced powerlifting on street exercise equipment, reliability was revealed at $p<.01$ in men with a PI coefficient below the average $(<3.53)$, compared with athletes with a PI coefficient above the average $(>$ 3.53 ) with a $p<.05$. The obtained indicators prove that the effectiveness of powerlifting on street simulators with a variable load depends on the initial strength indicators of athletes. The lower the athletic performance for women and men, the greater the increase in strength indicators is possible with the implementation of street training fitness and vice versa. This result can be explained by the fact that the street space for physical exercises does not have a sufficient stimulating effect on more trained athletes in the strength direction. Psychological factors when performing maximum power loads in public, especially when implementing 
constraint in women, may have had a restraining effect on a significant increase in the result. Or, it can be assumed that in order to increase the power qualities of stronger athletes, special conditions for powerlifting in the gym are especially necessary. The empirical proof of the revealed provisions requires a separate experimental study in further scientific works.

\section{DISCUSSION}

The results obtained in this experiment are consistent with the proven results of other studies analysing the increase in physical activity in parks and yard areas among the middle and younger population (Chow et al., 2017; Lacharite-Lemieux \& Dionne, 2016; Taipe-Nasimba et al., 2019). A theoretical analysis of studies on this problem substantiates that systematic physical activity is both a positive and a preventive factor for maintaining the physical development of youth (Kharisov et al., 2017; Sibson et al., 2018). The need to modernize the training process in power sports, in particular the experimental identification of new directions in the training of powerlifters, is gaining relevance with every decade (Dodonov \& Shutova, 2013; Radenkovic \& Nesic, 2018). Various modernization technologies are proposed from methodological, biomedical to tactical and organizational conditions (Yakubenko, 2016, Ogulchansky \& Sedyh, 2017). It is from the perspective of accounting for the latter condition that the author's study was carried out and experimentally proven positive results were obtained.

The study complements the comparative results obtained between outdoor and indoor exercises (Aspinall et al., 2015; Thompson et al., 2011). Which experimentally substantiates the positive dynamics of classes outside the gym (Chow et al., 2019; Mora, 2012). In this aspect, a study by a group of scientists (Calogiuri \& Elliott, 2017; Manferdelli et al., 2019), which presents statistical data on the motivation of young people to do free fitness, is interesting. Scientists have proven that the provision of freely available simulators for exercise can increase the physical activity of the population and further increase athletic performance (Mora, 2012; Copeland et al., 2017). This is also proved by the results obtained in our study. The effectiveness of the classes was not only to increase strength by increasing the amount of weight in three exercises, but also to reduce the excess body weight of students (Lacharite-Lemieux \& Dionne, 2016; Kharisov et al., 2017). This was especially evident in men with a body weight of more than 80 kilograms. Which in turn influenced the increase in the powerlifters coefficient $(\mathrm{PI})$ and the effectiveness of the study.

In many studies, the authors prove that training on street fitness equipment is a key factor not only in recreational and corrective conditions (Allen-Collinson \& Leledaki, 2015; Lee et al., 2018), but also in the physical development of athletes of various qualifications (Kharisov et al., 2017). The study enriched the process of implementing physical culture and sports activities at the place of residence (Ries et al., 2009). In turn, in the Russian Federation, this direction is gaining relevance, a theoretical and methodological base and its practical implementation (Nagovitsyn et al., 2019). The data obtained after the implementation of the experiment prove psychological changes in the population in the perception of physical activity on the street (Calogiuri \& Elliott, 2017; Thompson et al., 2011). The effectiveness of a study conducted in free space is one of the most important psychological conditions in the training process of a powerlifter (Kharisov et al., 2017; Manferdelli et al., 2019). It is the environment and free space that can determine the ability of women and men to perform strength exercises with higher maximum efficiency. This may also be the justification for data on improving the performance of men $(p<.01)$, since they are more susceptible to psychological influence from spectators and fans. However, this will require additional experimental studies to verify these statements in the future. 


\section{CONCLUSIONS}

The study proved a reliable positive effect of powerlifting on street exercise machines with a variable load. It was experimentally proved that in groups of men significantly increased athletic performance in the experimental compared to the control group. The implementation of the training process of youth in powerlifting on street fitness equipment in the summer can significantly increase strength indicators in women and men.

The study proposed an original monitoring powerlifter coefficient (PI). It allows you to take into account not only the amount of weight overcome by type (bench press, squat, deadlift), but the individual body weight of the athlete. This makes it possible to evaluate the result of an athlete regardless of his belonging to a specific weight category. And not only in increasing the overcoming of maximum weight, but also take into account the number of kilograms burned in body weight.

The practical significance of the study lies in the fact that classes on street simulators can be used in preparation for competitions in powerlifting. This process will allow to reach a higher quality level of organization of physical culture and sports activities at the place of residence, providing individual physical development of each athlete. The presented practical implementation experience can be used in the construction of physical culture and sports space in other sports to increase the quantity of the population actively involved in physical education and sports. The data obtained are especially valuable in the condition of the activation of street fitness among women and men in the conditions of the closure of gyms caused by the regime of self-isolation during the spread of COVID-19.

\section{CONFLICT OF INTEREST}

There were no conflicts of interest.

\section{REFERENCES}

Allen-Collinson, J., \& Leledaki, A. (2015). Sensing the outdoors: a visual and haptic phenomenology of outdoor exercise embodiment. Leisure Studies, 34(4), 457-470. https://doi.org/10.1080/02614367.2014.923499

Aspinall, P., Mavros, P., Coyne, R., \& Roe, J. (2015). The urban brain: analysing outdoor physical activity with mobile EEG. British journal of sports medicine, 49(4), 272-291. https://doi.org/10.1136/bjsports2012-091877

Babey, S.H., Hastert, T.A., Yu, H., \& Brown, E.R. (2008). Physical activity among adolescents. When do parks matter? American journal of preventive medicine, 4, 345-348. https://doi.org/10.1016/.amepre.2008.01.020

Ball, R., \& Weidman, D. (2018). Analysis of USA powerlifting federation data from january 1, 2012-june 11, 2016. Journal of strength and conditioning research, 32(7), 1843-1851. https://doi.org/10.1519/jsc.0000000000002103

Bedimo-Rung, A.L., Mowen, A.J., \& Cohen, D.A. (2005). The significance of parks to physical activity and public health: A conceptual model. American Journal of Preventive Medicine, 28(2), 159-168. https://doi.org/10.1016/.amepre.2004.10.024

Calogiuri, G., \& Elliott, L.R. (2017). Why Do People Exercise in Natural Environments? Norwegian Adults' Motives for Nature-, Gym-, and Sports-Based Exercise. International journal of environmental research and public health, 14(4), 377. https://doi.org/10.3390/ijerph14040377 
Chow, H.W., Mowen, A.J., \& Wu, G.L. (2017). Who is using outdoor fitness equipment and how? The case of Xihu Park. International Journal of Environmental Research and Public Health, 14(4), 448. https://doi.org/10.3390/ijerph14040448

Chow, H.W., \& Wu D.R. (2019). Outdoor Fitness Equipment Usage Behaviors in Natural Settings. International journal of environmental research and public health, 16(3), 391. https://doi.org/10.3390/ijerph16030391

Church, J.B., Allen, T.N., \& Allen, G.W. (2016). A Review of the Efficacy of Weight Training Aids. Strength and conditioning journal, 38(3), 11-17. https://doi.org/10.1519/ssc.0000000000000227

Cleather, D.J. (2006). Adjusting powerlifting performances for differences in body mass. Journal of strength and conditioning research, 20(2), 412-421. https://doi.org/10.1519/00124278-200605000$\underline{00030}$

Coker, N.A., Varanoske, A.N., Baker, K.M., Hahs-vaughn, D.L., \& Wells, A.J. (2018). Predictors of competitive success of national-level powerlifters: a multilevel analysis. International journal of performance analysis in sport, 18(5), 796-805. https://doi.org/10.1080/24748668.2018.1519751

Copeland, J.L., Currie, C., Walker, A, Mason, E., Willoughby, T.N., \& Amson, A. (2017). Fitness Equipment in Public Parks: Frequency of Use and Community Perceptions in a Small Urban Centre. Journal of Physical Activity and Health, 5, 344-352. https://doi.org/10.1123/jpah.2016-0277.

Cranney, L., Phongsavan, P., Kariuki, M., Stride, V., Scott, A., Hua, M., \& Bauman, A. (2016). Impact of an outdoor gym on park users' physical activity. A natural experiment Health and Place, 37, 26-34. https://doi.org/10.1016/i.healthplace.2015.11.002

Dodonov, A.P., \& Shutova, T.N. (2013). Training qualified powerlifters based on a biorhythm approach. Teoriya i Praktika Fizicheskoy Kultury, 10, 78-80.

Galan, Y., Nakonechnyi, I., Moseichuk, Y., Vaskan, I., Paliichuk, Y., \& Yarmak, O. (2017). The analysis of physical fitness of students of 13-14 years in the process of physical education. Journal of Physical Education and Sport, 17(S5), 2244-2249. https://doi.org/10.7752/ipes.2017.s5237

Garipova, A.Z., Zotova, F.R., \& Askhamov, A. A. (2017). Enhancing the preparation of students for the surrender of athletic standards through exercises of powerlifting. Indo American journal of pharmaceutical sciences, 4(9), 3095-3100. https://doi.org/10.5281/zenodo.911020

Hug, S.M., Hartig, T., Hansmann, R., Seeland, K., \& Hornung, R. (2009). Restorative qualities of indoor and outdoor exercise settings as predictors of exercise frequency. Health \& place, 15(4), 971-980. https://doi.org/10.1016/i.healthplace.2009.03.002

Kharisov, I.D., Nenasheva, A.V., Aminov, A.S., Cieslicka, M.Z., \& Mushketa, R.K. (2017) Assessment of physical fitness indicators in students practicing powerlifting and street workout. Human Sport Medicine, 1(17), 67-78. https://doi.org/10.14529/hsm170107

Kudryavtsev, M. D., Kramida, I. E., lermakov, S. S., Osipov, A. Yu. (2016). Development dynamic of healthy life style personality component in relatively healthy students. Physical Education of Students, 20(6), 26-33. https://doi.org/10.15561/20755279.2016.0603

Lacharite-Lemieux, M. \& Dionne, I.J. (2016). Physiological Responses to Indoor Versus Outdoor Training in Postmenopausal Women. Journal of aging and physical activity, 24(2), 275-283. https://doi.org/10.1123/japa.2015-0019

Lee, J.L.C., Lo, T.L.T., \& Ho, R.T.H. (2018). Understanding Outdoor Gyms in Public Open Spaces: A Systematic Review and Integrative Synthesis of Qualitative and Quantitative Evidence. International journal of environmental research and public health, 15(4), 590. https://doi.org/10.3390/ijerph15040590

Lesuer, D.A., Mccormick, J.H., Mayhew, J.L., Wasserstein, R.L. \& Arnold, M.D. (1997). The Accuracy of Prediction Equations for Estimating 1-RM Performance in the Bench Press, Squat, and Deadlift. 
Journal of Strength and Conditioning Research, 11(4), 211-213. https://doi.org/10.1519/00124278199711000-00001

Manferdelli, G., La Torre, A. \& Codella, R. (2019). Outdoor physical activity bears multiple benefits to health and society. Journal of sports medicine and physical fitness, 59(5), 868-879. https://doi.org/10.23736/s0022-4707.18.08771-6

Mora, R. (2012). Moving Bodies: Open Gyms and Physical Activity in Santiago. Journal of Urban Design, 17(4), 485-497. https://doi.org/10.1080/13574809.2012.706367

Nagovitsyn, R.S., Bartosh, D.K., Ratsimor, A.Y., \& Neverova, N.V. (2019). Modernization of Regional Continuing Pedagogical Education in the "School-College-Institute. European journal of contemporary education, 8(1), 144-156. https://doi.org/10.13187/ejced.2019.1.144

Nagovitsyn, R. S., Miroshnichenko, A. A., \& Senator, S. Yu. (2018). Implementation of mobile pedagogy during continuous education of physical culture teachers. Integration of Education, 22(1), 107-119. https://doi.org/10.15507/1991-9468.090.022.201801.107-119

Nagovitsyn, R.S., Tutolmin, A.V., Maksimov, Y.G., Dimova, I.A., Karoyan, A.A., Skryabina, D.Y., \& Volkov, S.A. (2019). Motivation for physical activity of people of different ages. Gazzetta Medica Italiana - Archivio per le Scienze Mediche, 178(10), 799-806. https://doi.org/10.23736/s0393$\underline{3660.18 .03965-7}$

Nagovitsyn, R. S., Volkov, P. B. \& Miroshnichenko, A. A. (2017). Planning of physical load of annual cycle of students', practicing cyclic kinds of sports, training. Physical education of students, 21(3), 126-133. https://doi.org/10.15561/20755279.2017.0305

Nagovitsyn R. S., Zekrin F. H., Fendel' T. V., \& Zubkov, D. A. (2019). Sports selection in martial arts based on the harmonic stability of results at competitions. Journal of Human Sport and Exercise, 14(4proc), S867-S876. https://doi.org/10.14198/jhse.2019.14.proc4.49

Ogulchansky, V.A., \& Sedyh, N.V. (2017). Features of the organization of the training process in powerlifting. Teoriya i Praktika Fizicheskoy Kultury, 7, 80.

Osipov, A., lermakov, S., Gruzinky, V., Kudryavtsev, M., Bliznevsky, A., Bliznevskaya, V., Serzhanova, Z., Kuzmin, V., Zhavner, T., Vapaeva, A., Markov, K., \& Kondrashova, E. (2018). Analysis of the parameter changes of students' physical development (At the age of 18-20) to identify the threat of increased body weight and obesity. Journal of Physical Education and Sport, 18(2), 800-809. https://doi.org/10.7752/jpes.2018.02118

Osipov, A., Kudryavtsev, M., Fedorova, P., Serzhanova, Z., Panov, E., Zakharova, L., Savchuk, A., Yanova, M., Zhavner, T., \& Klimuk, Y. (2017). Components of positive impact of exposure on university physical culture and sports on students' physical activity. Journal of Physical Education and Sport, 17(2), 871-878. https://doi.org/10.7752/jpes.2017.02133

Radenkovic, L., \& Nesic, L. (2018). The physics of powerlifting. European journal of physics, 39(3), 034002. https://doi.org/10.1088/1361-6404/aaa90e

Ries, A.V., Voorhees, C.C., Roche, K.M., Gittelsohn, J., Yan, A.F., \& Astone, N.M. (2009). A quantitative examination of park characteristics related to park use and physical activity among urban youth. Journal of adolescent health, 8, 64-70. https://doi.org/10.1016/j.jadohealth.2009.04.020

Şar N.Ş., Soyer F., \& Koç M. (2018). An analysis of psychological endurance and personality traits of individuals doing sports and not doing sports by various variables. Physical education of students, 22(2), 91-98. https://doi.org/10.15561/20755279.2018.0206

Sanchez-Martinez, J., Plaza, P., Araneda, A., Sanchez, P., \& Almagia, A. (2017). Morphological characteristics of Street Workout practitioners. Nutricion hospitalaria, 34(1), 122-127. https://doi.org/10.20960/nh.987 
Sibson, R., Scherrer, P., \& Ryan, M.M. (2018) 'I think it adds value, but I don't use it': use, perceptions and attitudes of outdoor exercise equipment in an urban public park. Annals of Leisure Research, 21(1), 58-73. https://doi.org/10.1080/11745398.2017.1290535

Taipe-Nasimba, N., Peris-Delcampo, D., \& Cantón, E. (2019). Motives for sports practice, psychological well-being and immigration in Street Workout practitioners. Revista De Psicologia Del Deporte, 28(2), 135-142. Retrieved from https://www.rpd-online.com/article/view/v28-n2-taipe-peris-canton

Thompson, C.T., Boddy, K., Stein, K., Whear, R., Barton, J., \& Depledge, M.H. (2011). Does Participating in Physical Activity in Outdoor Natural Environments Have a Greater Effect on Physical and Mental Wellbeing than Physical Activity Indoors? A Systematic Review. Environmental science \& technology, 45(5), 1761-1772. https://doi.org/10.1021/es102947t

Yakubenko, Y.E. (2016). Training load partitioning by lift groups in powerlifting. Teoriya i praktika fizicheskoy kultury, 6, 76-78.

Yarmak, O., Blagii, O., Palichuk, Y., Hakman, A., Balatska, L., Moroz, O., \& Galan, Y. (2018). Analysis of the factor structure of the physical condition of girls 17-19 year-old. Journal of Human Sport and Exercise, 13(2proc), S259-S268. https://doi.org/10.14198/jhse.2018.13.proc2.11

\section{@(@) $\Theta \Theta$}

This work is licensed under a Attribution-NonCommercial-NoDerivatives 4.0 International (CC BY-NC-ND 4.0). 